\title{
Nutritional Status of Children Seeking Medical Treatment in a Rural Hospital in Ilam District, Nepal
}

\author{
Paneru $\mathrm{C}^{1}$, George $\mathrm{SM}^{2}$
}

\begin{abstract}
Introduction: Childhood malnutrition is a leading cause of mortality and morbidity in children under five years in Nepal. There is evidence to show that childhood malnutrition varies from region to region, within Nepal. But there is no data available about nutritional status of children in the 75 districts in Nepal. The aim of this study was to evaluate the nutritional status of children less than five years of age in Ilam district. Material and Methods: We analysed the anthropometric data for the children of Ilam district who visited Dr. Megh Bahadur Parajuli Community Hospital in Ilam district. Results: Our data showed that $15.7 \%$ of girls and $21.2 \%$ of boys under-five years suffered from moderate malnutrition. Severe malnutrition was present in $6.7 \%$ of girls and $9.6 \%$ of boys. Stunting was seen in $32.6 \%$ girls and $30.16 \%$ boys. Moderate stunting was present in $19.6 \%$ of girls and $19 \%$ of boys; while severe stunting was present in $11 \%$ of the boys and $13 \%$ of the girls. Conclusion: Our data shows that stunting among under-fives in llam is less as compared to that reported for Nepal, but underweight is comparable to the national data. However, a systematic study needs to be carried out in Ilam before drawing firm conclusions.
\end{abstract}

Key words: Under-fives, Nutrition, Malnutrition, Ilam, Nepal

\section{Introduction}

$\mathrm{N}$ epal demographic health survey reported that $41 \%$ of children under five years were stunted, $11 \%$ wasted and $29 \%$ underweight ${ }^{1}$. Several factors were noted to contribute towards malnutrition- for example, socio-economic factors, mother's literacy, acute illnesses, age of the child ${ }^{2}$. Social problems such as poverty, skewed land distribution and food insecurity are some of the underlying factors which cause malnutrition ${ }^{3}$. Several independent studies have been carried out in Nepal, estimating the prevalence of acute malnutrition to be anywhere from 8-18\%, as measured by MUAC ${ }^{4,5,6}$. World Health Organisation (WHO) data from 2011 report the prevalence of moderate and severe malnutrition to be $29.8 \%$ and $8.5 \%$ respectively, among boys under five in Nepal. These figures were 28.4 and 7.7 respectively for girls in the same age group. Moderate and severe stunting among Nepali boys who are under five were reported to be $41.3 \%$ and $16.8 \%$ respectively, and that among girls were $39.5 \%$ and $15.8 \%$ respectively ${ }^{7}$.

1Dr, Chandra Paneru, MBBS, ${ }^{2}$ Dr. Susan M. George MBBS, MRCPCH, PhD. Both from Dr. Megh Bahadur Parajuli Community Hospital, llam.

\author{
Address for correspondence: \\ Dr. Susan M. George \\ Dr. Megh Bahadur Parajuli Community Hospital, \\ Ilam, Nepal. \\ E-mail: susanmarygeorge@hotmail.com \\ Tel: +254 705963951
}

\section{How to cite}

Paneru C, George SM. Nutritional Status of Children Seeking Medical Treatment in a Rural Hospital in Ilam District, Nepal. J Nepal Paediatr Soc 2014;34(3):215-220.

doi: http://dx.doi.org/10.3126/jnps.v34i3.10737

This work is licensed under a Creative Commons Attribution 3.0 License.

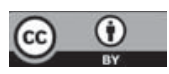

Malnutrition is not evenly distributed throughout Nepal. It varies ecologically and regionally. Stunting, wasting and underweight is reported to be much higher in the mountains compared to the national average $^{8}$. Children from Newar community were found to be more malnourished, in a report from Kathmandu (9). Previous study from Mugu district in the mid-Western region of Nepal reports that $18 \%$ of children under five years were malnourished (10). Data from Jirel in Eastern Nepal showed that $36.25 \%$ and $12.62 \%$ children under five years of age had mild to moderate and severe malnutrition respectively based on their MUAC measurements. The prevalence 
of stunting among girls were higher than that in boys in Jirel ${ }^{4}$.

Nepal is divided into 75 administrative districts. Ilam district is situated in the hilly Eastern part of Nepal, and has a total population of over 300,000 . Population of Ilam belongs to several castes, the major ones being Rai, Limbu, Bahun and Chhtri. Dr. Megh Bahadur Parajuli Community Hospital (DMBPCH) is located in rural Ilam district and is one of the 2 hospitals in Ilam district. Most of our patients come from Ilam district, although a small number of patients also come from nearby districts of Panchthar and Taplejung. There are no published reports on the prevalence of malnutrition among children in llam or nearby districts to date. Hence we undertook an analysis of the anthropometric data available to us from the children who visited our facility in order to understand the prevalence of malnutrition among under-fives in llam district.

\section{Materials and Methods}

We analysed the anthropometric data which was collected from children during their visits to our paediatric clinics at the hospital and in the community over 2010-2011. Data available to us were the weight, height and gender of the children (it was not routine practice in our Paediatric clinics to measure mid upper arm circumference (MUAC)). All the observations were measured by the same person on the calibrated equipments used in the paediatric clinic. Data from all the children who had chronic medical conditions and/ or severe acute medical conditions were excluded, in order to obtain a representative sample of children from Ilam district. Observations from children with acute medical conditions such as gastroenteritis which are likely to affect the anthropometry were also excluded from this dataset.

Weights for age and heights for age for a total of 193 children under the age of 5yrs (89 boys and 104 girls) who attended the paediatric clinic in our hospital during 2010-11 were plotted on WHO growth charts. Moderate and severe acute malnutrition and stunting was determined as 2 and 3 standard deviations (SD) respectively below the mean z-scores for the weight for age and height for age respectively, as per the WHO guidelines.

\section{Results}

Weight for age data was available for 193 children (89 boys and 104 girls), and height for age data for 109 children (46 girls and 63 boys) under five years of age. We excluded the children with severe acute or chronic medical conditions which had the potential to affect their nutritional status. In our group, $15.7 \%$ girls and $21.2 \%$ of the boys suffered from moderate malnutrition, and $6.7 \%$ girls and $9.6 \%$ boys suffered from severe malnutrition. A total of $19 \%$ of boys and $19.6 \%$ of girls suffered from moderate stunting; and $11 \%$ of boys and $13 \%$ of girls suffered from severe stunting.

It can be noted that below 1year of age, there was more uniform distribution of the weights around the mean. In the $>1.5 \mathrm{yr}$ age groups, the weights of majority of children fell below the mean z-scores, as can be seen from the graphs.

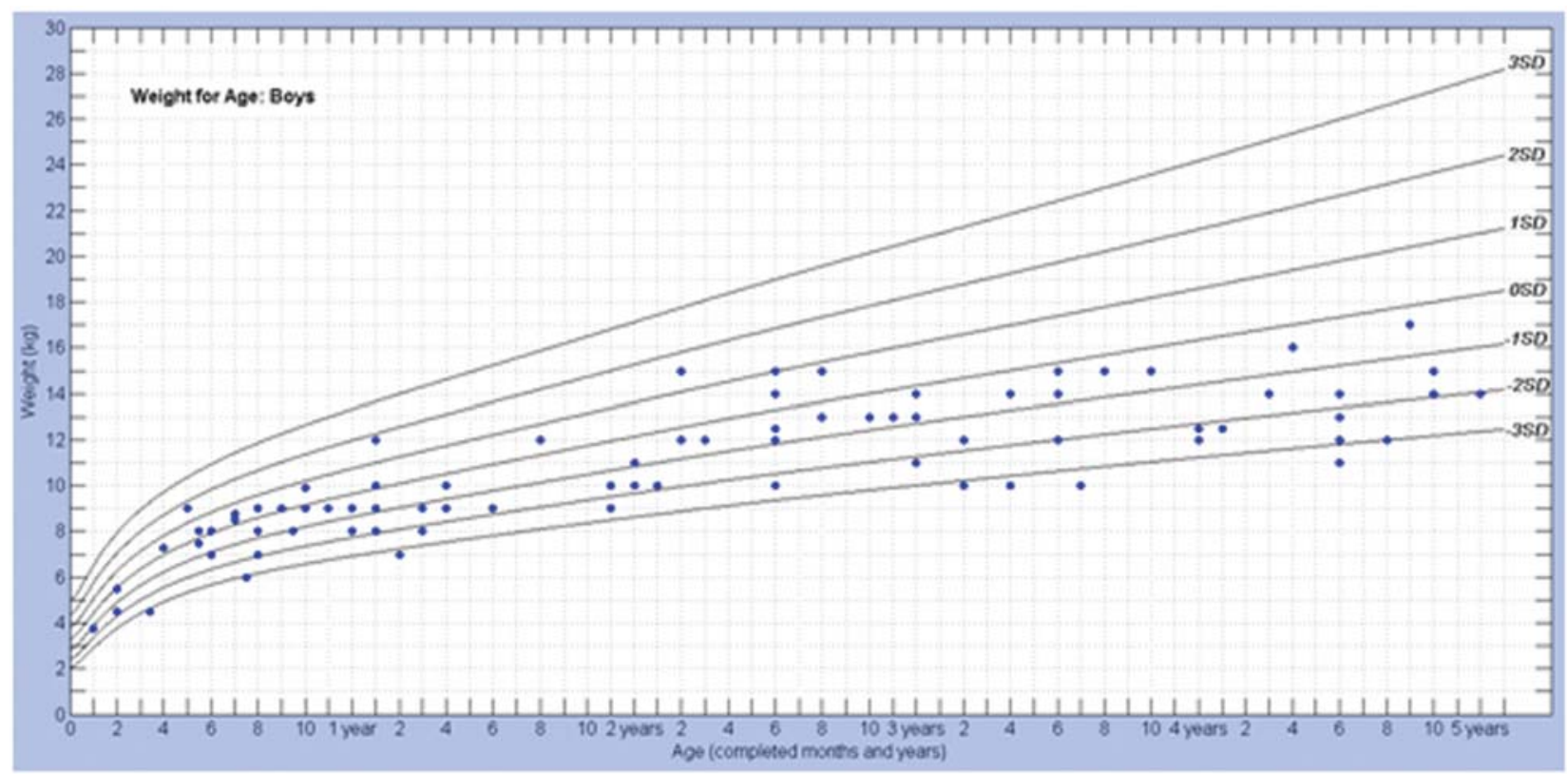

Fig 1: Weight for age in boys under 5 years in llam district $(n=104)$ 
Table 1: Malnutrition in boys under 5 years in Ilam district $(n=104)$

\begin{tabular}{|l|c|}
\hline Malnutrition in boys & Proportion of boys \\
\hline Boys with moderate malnutrition & $21.2 \%$ \\
\hline Boys with severe malnutrition & $9.62 \%$ \\
\hline Malnutrition in boys under 5 years (moderate \& severe) & $30.77 \%$ \\
\hline
\end{tabular}

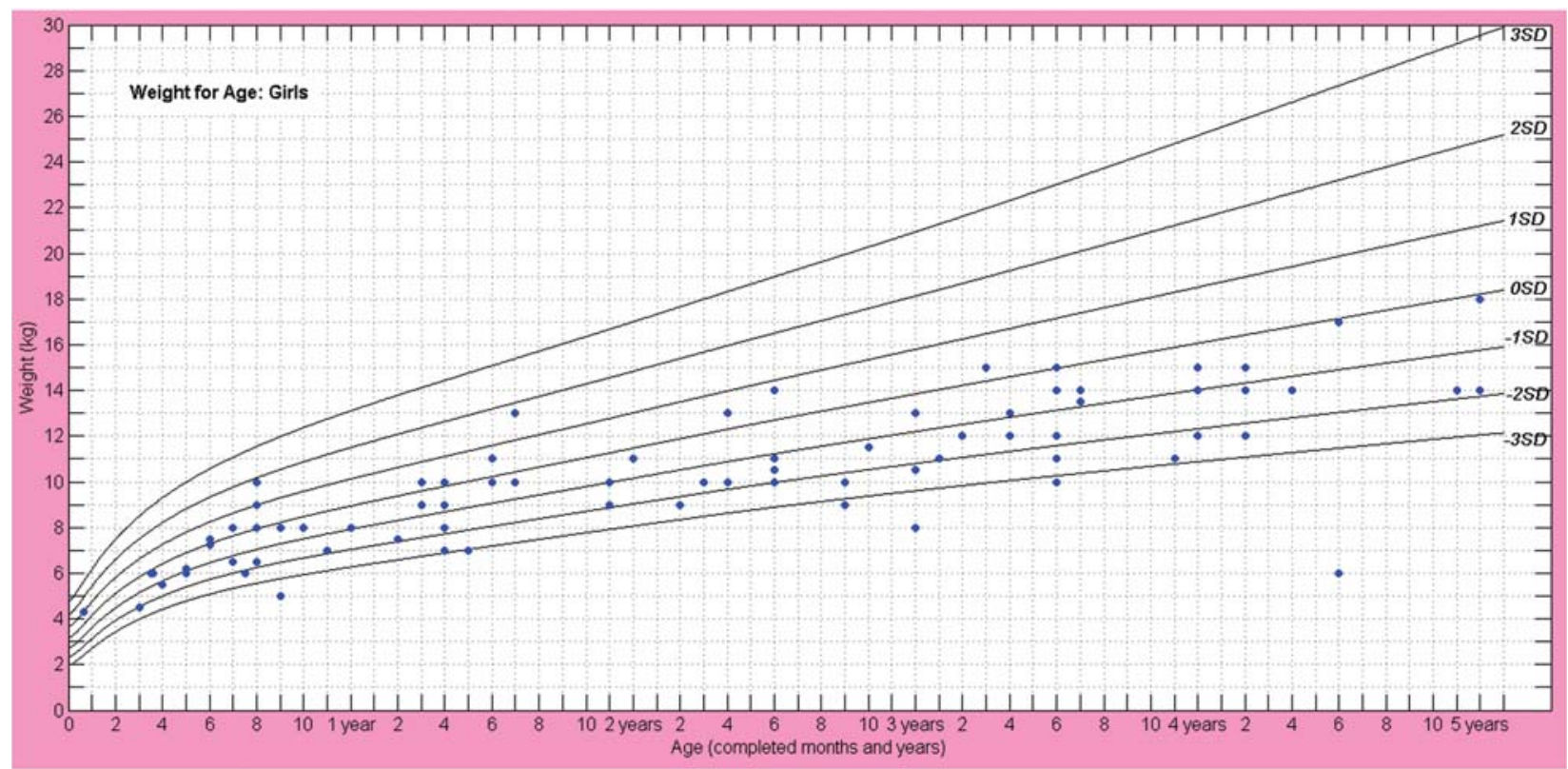

Fig 2: Weight for age of girls under 5 years in llam $(n=89)$

Table 2: Malnutrition among girls under 5 years in Ilam $(n=89)$

\begin{tabular}{|l|c|}
\hline Malnutrition in girls & Proportion of girls \\
\hline Girls with moderate malnutrition & $14.6 \%$ \\
\hline Girls with severe malnutrition & $7.87 \%$ \\
\hline Girls under 5 years with malnutrition (moderate \& severe) & $22.47 \%$ \\
\hline
\end{tabular}

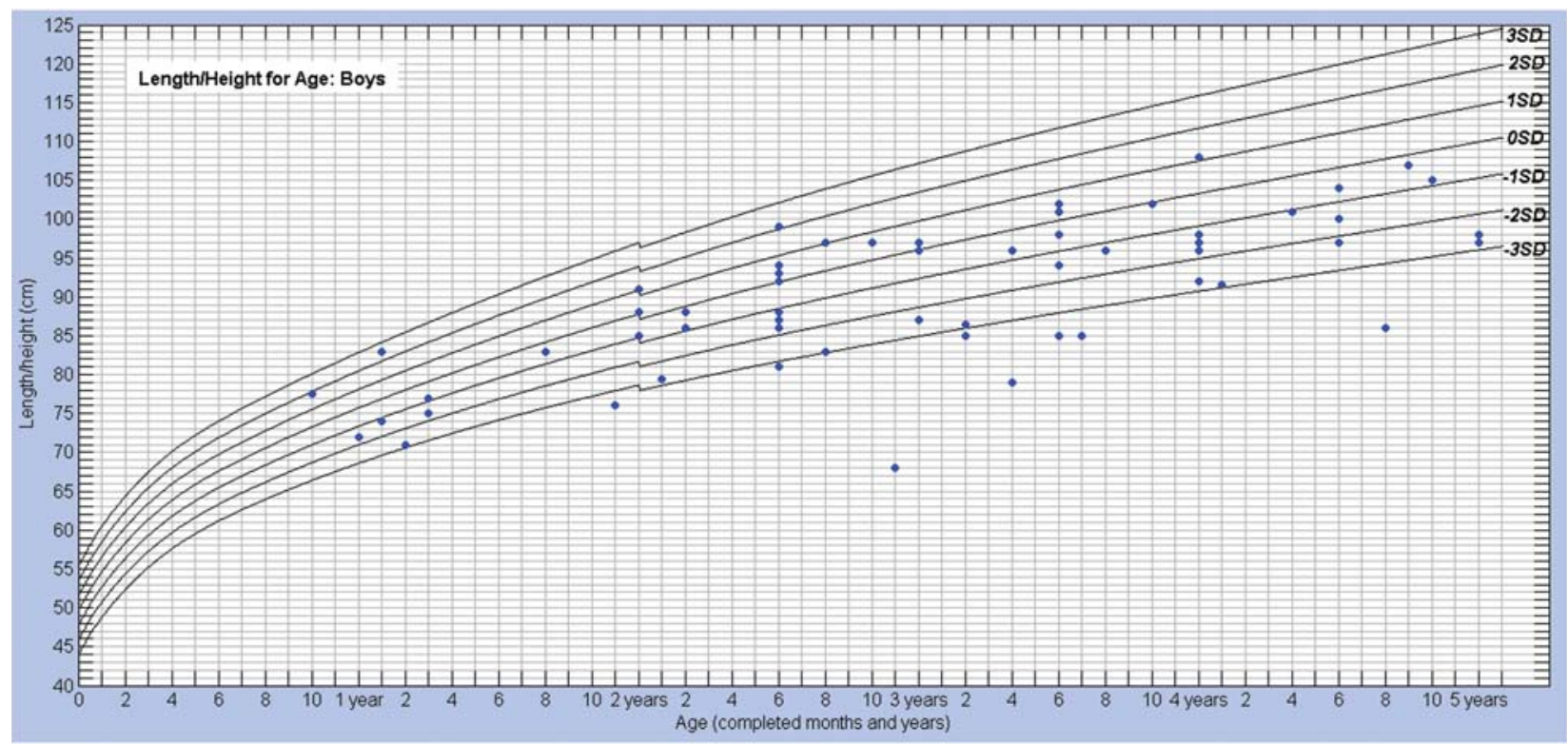

Fig 3: Height for age among the boys in Ilam district $(n=63)$ 
Table 3: Stunting among the boys in Ilam district $(n=63)$

\begin{tabular}{|l|c|}
\hline Stunting in boys & Proportion of boys \\
\hline Boys with moderate stunting & $19 \%$ \\
\hline Boys with severe stunting & $11 \%$ \\
\hline Boys under 5 years with stunting (moderate \& severe) & $30.16 \%$ \\
\hline
\end{tabular}

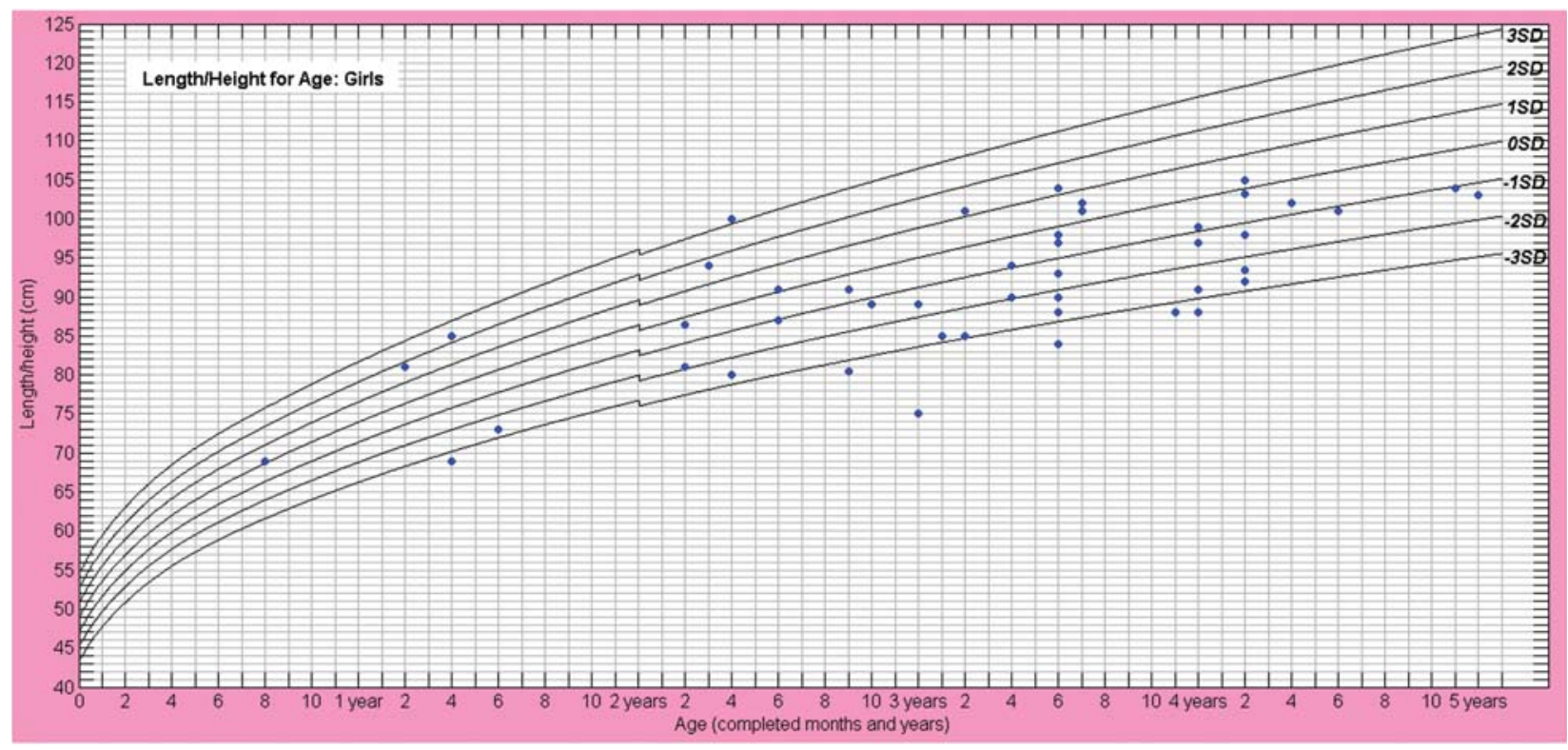

Fig 4: Height for age among girl in Ilam district $(n=46)$

Table 4: Stunting among girl in Ilam district $(n=46)$

\begin{tabular}{|l|c|}
\hline Stunting in girls & Proportion of girls \\
\hline Girls with moderate stunting & $19.57 \%$ \\
\hline Girls with severe stunting & $13.04 \%$ \\
\hline Girls under 5 years with stunting (moderate \& severe) & $32.6 \%$ \\
\hline
\end{tabular}

\section{Discussion}

Malnutrition is a major problem among underfives in Nepal, contributing to significant morbidity and mortality in this group. Our data from Ilam reveals that the prevalence of moderate malnutrition among under-fives is less than that reported in all of Nepal. As is apparent from the national data, malnutrition becomes worse after 18 months of age ${ }^{1}$.

Overall, our data reveals that malnutrition among under-fives is lesser in llam district compared to the national data for under-fives. There was evidence of a much lower prevalence of stunting (decreased weight for age) in Ilam when compared with the national figures ${ }^{1,7}$. The latter finding may be because of the small data set in our group, compared with the national data for Nepal.

Our data shows that the nutritional status of children under five in Ilam in 2010-11 was better in comparison to the data from Jirel, from $2005^{4}$ and Sarlahi ${ }^{6}$. The prevalence of malnutrition and stunting seen in Ilam was more than that reported from Mugu district, and much higher compared to the prevalence of malnutrition in Humla district, in the study carried out by Thapa et al. ${ }^{10,11}$. Stunting was more in girls than boys, a finding consistent with the data published from Dhankuta district ${ }^{12}$. There is a wide variation in the data published from different districts, although there were very few studies (see table).

There is no previously published data from Ilam district on malnutrition among under-fives. This makes our study an important step towards evaluation of the nutritional status of children in Ilam. By excluding the observations from all the children with chronic illnesses and severe acute illnesses, we believe that our data is representative of the nutritional status of children who are under five years of age in Ilam district. However, our data is based on a small cross-sectional observational dataset collected from children who visited our clinical Paediatric facility at DMBPCH or our village health clinics in Ilam. 


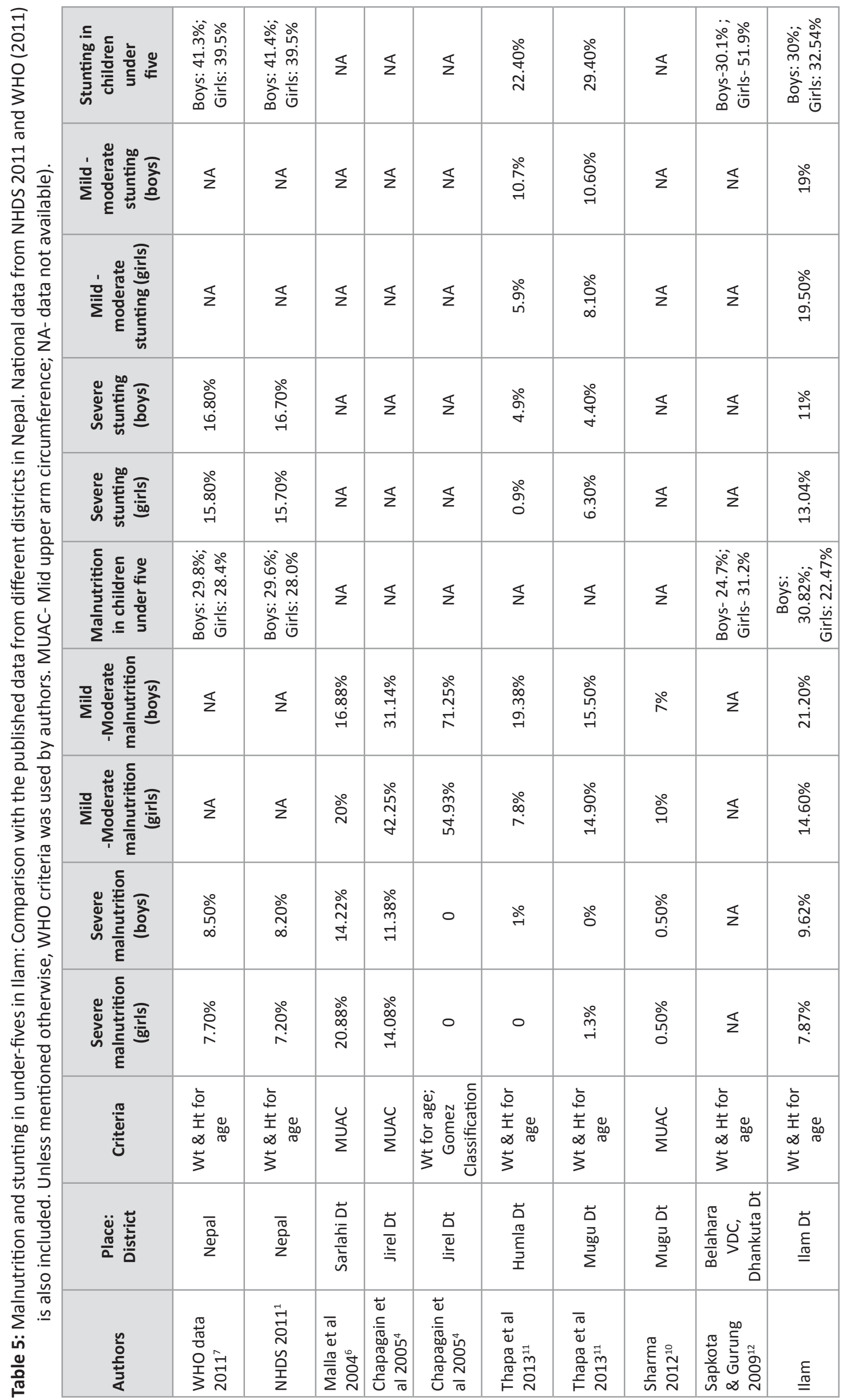


A larger study involving healthy children from all over llam district is required to fully understand the current nutritional status of under-fives in llam.

Acknowledgements: This work was carried out in $\mathrm{Dr}$ Megh Bahadur Parajuli Community Hospital (DMBPCH), Ilam, which is run by Himalayan Health Care (HHC). We are grateful to $\mathrm{HHC}$ and all the staff at $\mathrm{DMBPCH}$ for their support during our clinical work. We are grateful for the help from all the supporting staff, and in particular Mr Mukesh Siva for his assistance in collecting all the anthropometric data. We also thank Dr Anita Chan for her technical help in preparing the graphs which are included in this paper. This work would not have been possible without the cooperation of the children, their parents and the community in Ilam, to whom we express our sincere gratitude.

Funding: Nil

Conflict of Interest: Nil

Permission from IRB: Yes

\section{Reference}

1. Nepal demographic and health survey 2011. Kathmandu: Ministry of Health and Population.

2. Sah N, Determinants of child malnutrition in Nepal: A case analysis from Dhanusha, central Terai of Nepal. J Nepal Health Res Counc 2004;2(2):50-54.

3. Gurung G. Social determinants of protein-energy malnutrition: Need to attack the causes of the causes. J Health Popul Nutr 2010;28(3):308-9.

4. Chapagain RH, Adhikari AP, Dahal R, Subedi J, Bhengero J, Willams-Bhengero $S$ and Towne B. A study on Nutritional status of under 5 Jirel children of Eastern Nepal. J Nepal Health Res Counc 2005;3(2):39-42.

5. Singh S, BC RK, Simkhada P, and Van Teijlingen E. Health status and health needs of orphan children in Kathmandu, Nepal. J Nepal Health Res Counc 2007;5(2):39-48.

6. Malla B, Sherchand JB, Ghimire P, BC Rajendra Kumar, Gauchan P. Prevalence of intestinal parasitic infestation and malnutrition among children in a rural community of Sarlahi, Nepal. J Nepal Health Res Counc 2004;2(1):55-57.

7. WHO Global database on child growth and malnutrition: http://www.who.int/nutgrowthdb/ database/countries/npl/en/

8. Joshi PC. Malnutrition in children: A serious public health issue in Nepal. Health Prospect 2012;11:6162.

9. Malla S, Shrestha SM. Complementary feeding practices and its impact on nutritional status of under two old children in urban areas of the Kathmandu, Nepal. J Nepal Health Res Counc 2004;2(1):1-4.

10. Sharma KR. Malnutrition in children aged 6- 59 months in Mugu district. J Nepal Health Res Counc 2012;10(20):156-59.

11. Thapa M, Neopane AK, Singh UK, Aryal N, Agrawal $K$, Shrestha B. Nutritional status of children in two districts of the mountain region of Nepal. J Nepal Health Res Counc 2013;11(25):235-39.

12. Sapkota VP, Gurung CK. Prevalence and predictors of underweight, stunting and wasting in under-five children. J Nepal Health Res Counc 2009;7(5):12026. 